\title{
ARTICLE
}

\section{Development of boron sheet and DT neutron irradiation experiments of multi-layered concrete structure with boron sheet}

\author{
Satoshi Sato ${ }^{\mathrm{a}^{*}}$, Toshio Maegawa ${ }^{\mathrm{b}}$, Kenji Yoshimatsu ${ }^{\mathrm{b}}$, Koichi Sato $^{\mathrm{b}}$, Akira Nonaka ${ }^{\mathrm{b}}$, Kosuke Takakura $^{\mathrm{a}}$, \\ Kentaro Ochiai ${ }^{\mathrm{a}}$ and Chikara Konno ${ }^{\mathrm{a}}$ \\ ${ }^{a}$ Japan Atomic Energy Agency, 2-4 Shirakata, Tokai-mura, Naka-gun, Ibaraki-ken, 319-1195, Japan; \\ ${ }^{b}$ Kumagai gumi Co., 2-1 Tsukutotyo, Shinjyuku, Tokyo, 162-8557, Japan
}

\begin{abstract}
The boron sheet was developed in order to reduce induced activity in concrete walls applied for neutron generation facilities, and it was applied to a new multi-layered concrete structure. DT neutron irradiation experiments were performed by using multi-layered concrete structure mockups with the boron sheet at FNS in JAEA. It is demonstrated that the multi-layered concrete structure with the boron sheet can effectively reduce the low energy neutrons, which leads to less induced activity in concrete walls.
\end{abstract}

Keywords: boron sheet; concrete; DT neutron; FNS; shield experiment; multi-layered concrete structure

\section{Introduction}

In the previous study, we developed a multi-layered concrete structure to reduce induced activity in concrete walls applied for neutron generation facilities such as fusion reactor, fission reactor, and accelerator facilities [1]. This structure is composed of low activation concrete as the first layer, boron doped low activation concrete as the second layer and ordinary concrete as the third layer from the side of the neutron source. The first layer moderates fast neutrons, and the slowing-down neutrons are effectively absorbed in the boron doped low activation concrete. Boron has a very large capture cross section for low energy neutrons. As a result, long-lived nuclei such as ${ }^{60} \mathrm{Co}$ (half life: $5.271 \mathrm{y}$ ) and ${ }^{152} \mathrm{Eu}$ (half life: 13.54 y) generated by low energy neutrons decrease in the ordinary concrete. By applying the low activation concrete, short-lived nuclei such as ${ }^{24} \mathrm{Na}$ (half life: 15.0 h) and ${ }^{56} \mathrm{Mn}$ (half life: $2.58 \mathrm{~h}$ ) also drastically decrease in the first layer. It is possible to access the concrete for the maintenance at shorter time. The boron-doped concrete is much more expensive than the ordinary concrete. In order to reduce the construction cost, as an alternative of the boron doped low activation concrete we developed a boron sheet in this study. In order to verify effects of the boron sheet on the reduction of low energy neutrons, DT neutron shielding experiments were performed using multi-layered concrete structure mockups with the boron sheet.

\section{Development of boron sheet}

The boron sheet was developed by doping the boron

*Corresponding author. Email: sato.satoshi92@jaea.go.jp carbonate to the methyl methacrylate (MMA) resin sheet. By changing the weight ratio of the boron carbonate to the MMA resin, and its thickness, we tested fabrication and uniformity of the boron sheet. From the test, we selected 1.0 as the weight ratio of the boron carbonate to the MMA resin in this study. The thickness of the boron sheet was $2 \mathrm{~mm}-6 \mathrm{~mm}$. The developed boron sheet also has good flexibility and sufficient strength for repeated bending. Figure 1 shows a picture of the boron sheet.

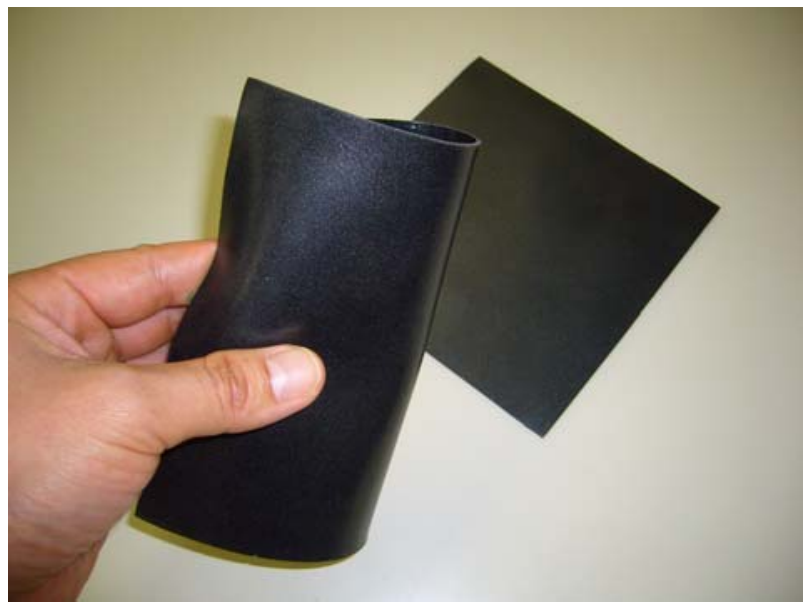

Figure 1. Picture of the boron sheet.

\section{Design of new multi-layered concrete structure}

We designed a new multi-layered concrete structure with the boron sheet. Figure $\mathbf{2}$ shows a concept of the multi-layered concrete structure. The first, second and 
third layers from the neutron source side are the low activation concrete of $20 \mathrm{~cm}$ in thickness, the boron sheet of $4 \mathrm{~mm}$ in thickness and the ordinary concrete of $30 \mathrm{~cm}$ in thickness, respectively.

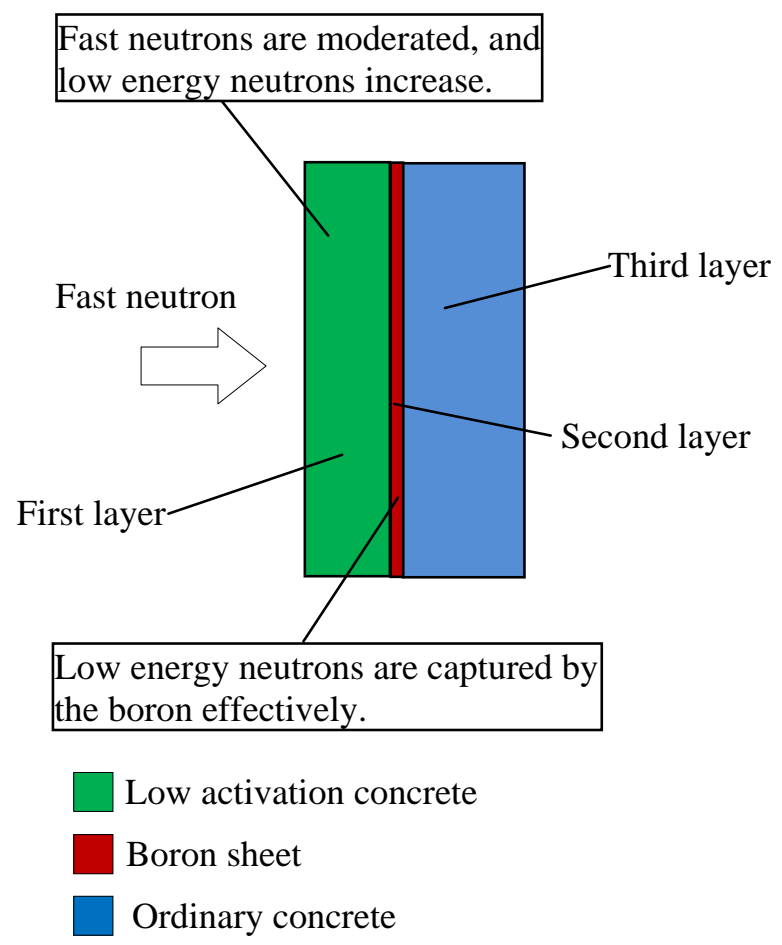

Figure 2. Concept of new multi-layered concrete structure.

Reaction rates of the ${ }^{59} \mathrm{Co}(\mathrm{n}, \gamma){ }^{60} \mathrm{Co}$ and ${ }^{151} \mathrm{Eu}(\mathrm{n}, \gamma){ }^{152} \mathrm{Eu}$ reactions in the multi-layered concrete structure were calculated with Monte Carlo calculation code MCNP5.14 [2] and Fusion Evaluated Nuclear Data Library FENDL-2.1 [3]. They gave an indication of the induced activities of ${ }^{60} \mathrm{Co}$ and ${ }^{152} \mathrm{Eu}$. In order to study the effect of the boron sheet thickness, we performed calculations changing the boron sheet thickness. For comparison, a calculation was done with the structure without the boron sheet. Table 1 shows the chemical composition of the concretes and the boron sheet used in this study. A symmetric point DT neutron source was generated at $10 \mathrm{~cm}$ distance from the concrete structure surface and its center. The width and height of these structures are assumed to be infinite in the calculation. Figure 3 shows reaction rate distributions of the ${ }^{59} \mathrm{Co}(\mathrm{n}, \gamma){ }^{60} \mathrm{Co}$ reaction as a function of the distance from the concrete structure surface for the structure with the boron sheet of $4 \mathrm{~mm}$ in thickness and that without one. By inserting the boron sheet between the concrete layers, the reaction rates of ${ }^{59} \mathrm{Co}(\mathrm{n}, \gamma){ }^{60} \mathrm{Co}$ can be drastically reduced. The reaction rates increase up to $15-20 \mathrm{~cm}$ depth for the structure without the boron sheet due to moderation of fast neutron, and they decrease over 20 $\mathrm{cm}$ depth. It is effective to insert the boron sheet at 20 $\mathrm{cm}$ depth. Figure 4 shows the ratio of the reaction rates of the ${ }^{59} \mathrm{Co}(\mathrm{n}, \gamma){ }^{60} \mathrm{Co}$ and ${ }^{151} \mathrm{Eu}(\mathrm{n}, \gamma){ }^{152} \mathrm{Eu}$ reactions integrated in the ordinary concrete with the boron sheet to those without one as a function of the boron sheet thickness. The boron sheet reduces the reaction rates to $1 / 2$ of those without the boron sheet. With increasing the boron sheet thickness, the reaction rates decrease slightly. When the thickness of the boron sheet is more than $4 \mathrm{~mm}$, decrease of the reaction rates is little. We adopted the boron sheet of $4 \mathrm{~mm}$ in thickness to the multi-layered concrete structure in this study.

Table 1. Chemical composition in the concretes and boron sheet used in this study (wt\%).

\begin{tabular}{cccc}
\hline Element & $\begin{array}{c}\text { Ordinary } \\
\text { Concrete }\end{array}$ & $\begin{array}{c}\text { Low Activation } \\
\text { Concrete }\end{array}$ & Boron Sheet \\
\hline $\mathrm{H}$ & 0.79 & 0.79 & 4.10 \\
$\mathrm{~B}$ & - & - & 38.28 \\
$\mathrm{C}$ & - & 9.16 & 41.21 \\
$\mathrm{O}$ & 50.19 & 49.18 & 16.41 \\
$\mathrm{Na}$ & 1.99 & 0.08 & - \\
$\mathrm{Mg}$ & 1.17 & 0.47 & - \\
$\mathrm{Al}$ & 7.19 & 0.52 & - \\
$\mathrm{Si}$ & 27.11 & 1.82 & - \\
$\mathrm{S}$ & 0.15 & 0.13 & - \\
$\mathrm{K}$ & - & 0.02 & - \\
$\mathrm{Ca}$ & 8.83 & 37.42 & - \\
$\mathrm{Mn}$ & - & 0.01 & - \\
$\mathrm{Fe}$ & 2.58 & 0.4 & - \\
\hline
\end{tabular}

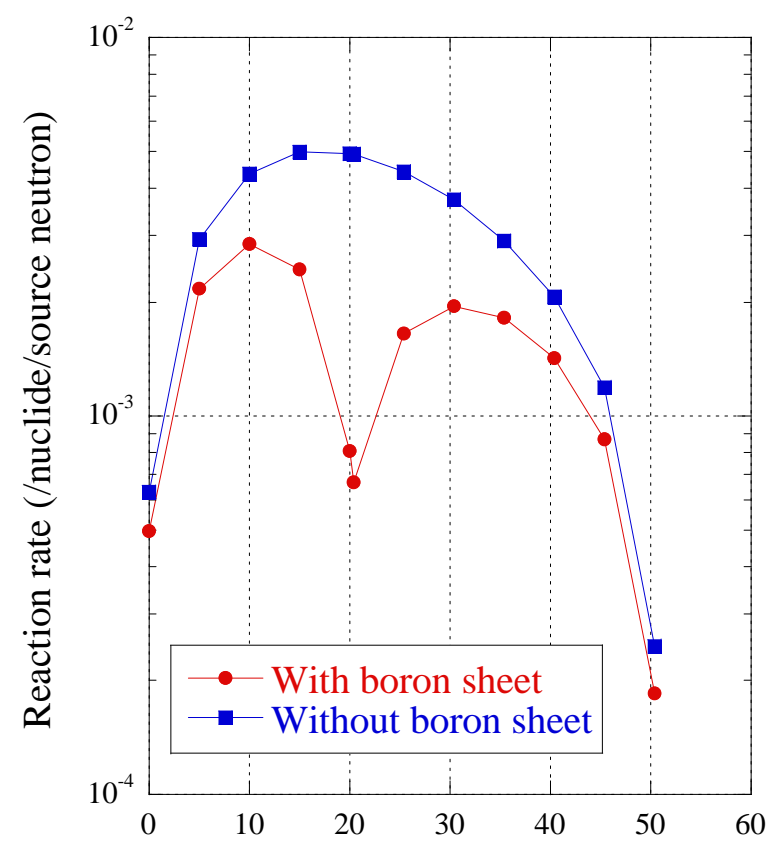

Distance from concrete structure surface $(\mathrm{cm})$

Figure 3. Reaction rate distributions of ${ }^{59} \mathrm{Co}(\mathrm{n}, \gamma){ }^{60} \mathrm{Co}$ for the structures with and without the boron sheet of $4 \mathrm{~mm}$ in thickness. 


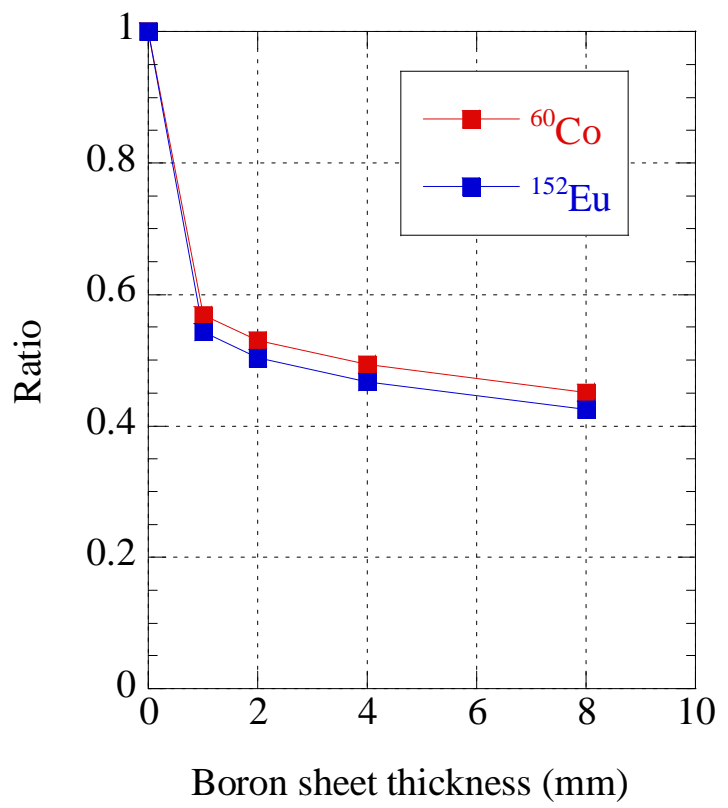

Figure 4. Ratio of the reaction rates of ${ }^{59} \mathrm{Co}(\mathrm{n}, \gamma)^{60} \mathrm{Co}$ and ${ }^{151} \mathrm{Eu}(\mathrm{n}, \gamma){ }^{152} \mathrm{Eu}$ integrated in the ordinary concrete with the boron sheet to those without one.

\section{DT neutron shielding experiment}

A DT neutron shielding experiments with four different multi-layered concrete structure mockups were conducted at the FNS (Fusion Neutronics Source) facility in JAEA. Figure 5 shows a picture of the multi-layered concrete mockup applied for the experiment. These mockups are about $30 \mathrm{~cm}$ in width, $30 \mathrm{~cm}$ in height and $50 \mathrm{~cm}$ in thickness. Structure- 1 has no boron sheet. Structure-2 is composed of the low activation concrete of $20 \mathrm{~cm}$ in thickness as the first layer, the boron sheet of $4 \mathrm{~mm}$ in thickness as the second layer and the ordinary concrete of $30 \mathrm{~cm}$ in thickness as the third layer. The numbers of the boron sheet increase in Structure-3 and Structure-4, and their effects were tested. In Structure-3 one more boron sheet is inserted at the $30 \mathrm{~cm}$ depth from the surface of Structure-2. Structure- 4 has one more boron sheet at $10 \mathrm{~cm}$ depth from the surface of Strucure-3.

As the neutron flux index, reaction rates of the ${ }^{197} \mathrm{Au}(\mathrm{n}, \gamma){ }^{198} \mathrm{Au}$ and ${ }^{93} \mathrm{Nb}(\mathrm{n}, 2 \mathrm{n}){ }^{92 \mathrm{~m}} \mathrm{Nb}$ reactions were measured every $5 \mathrm{~cm}$ in depth with gold and niobium foils. We adopted the gold foils of $1 \mu \mathrm{m}$ in thickness and $1 \mathrm{~cm}^{2}$ in area, and niobium foils of $1 \mathrm{~mm}$ in thickness and $1 \mathrm{~cm}$ in diameter. The ${ }^{197} \mathrm{Au}(\mathrm{n}, \gamma){ }^{198} \mathrm{Au}$ reaction is sensitive to low energy neutrons, which mainly contributes to the generation of long-lived radioactive nuclides, and the ${ }^{93} \mathrm{Nb}(\mathrm{n}, 2 \mathrm{n}){ }^{92 \mathrm{~m}} \mathrm{Nb}$ reaction is sensitive to neutrons above $10 \mathrm{MeV}$. The distance from the DT neutron source to the mockup surface was $10 \mathrm{~cm}$, and the average DT neutron yield at the neutron source was about $1.1-1.6 \times 10^{11}$ neutron/s. Total irradiation time was 4 - 6 hours for each mockup. After irradiation, gamma-rays from the activation foils were measured with high purity Ge detectors and reaction rates were derived.

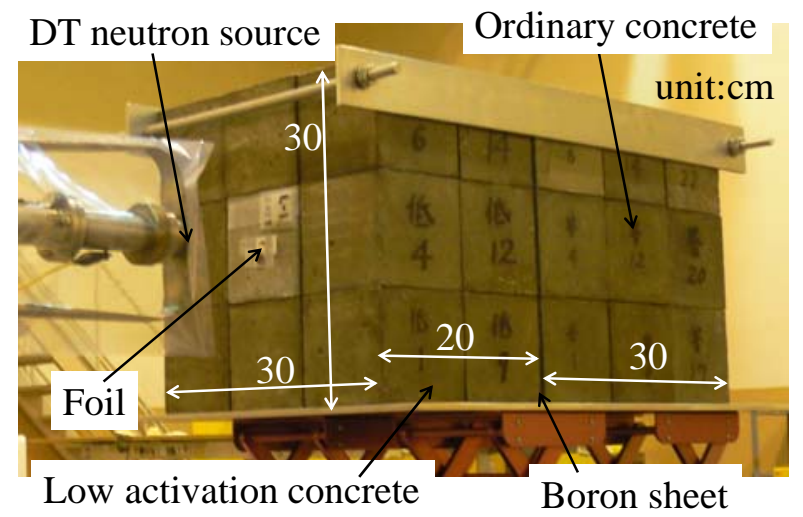

Figure 5. Picture of the multi-layered concrete mockup (Structure-2) applied for DT neutron shielding experiment.

\section{Results and discussion}

Figures 6 and 7 show the reaction rate distributions of ${ }^{93} \mathrm{Nb}(n, 2 n){ }^{92 m} \mathrm{Nb}$ and ${ }^{197} \mathrm{Au}(\mathrm{n}, \gamma){ }^{198} \mathrm{Au}$ in the multi-layered concrete structure mockups, respectively. The experimental errors are less than 5\%. There are no significant differences among the mockups for the reaction rate of ${ }^{93} \mathrm{Nb}(\mathrm{n}, 2 \mathrm{n})^{92 \mathrm{~m}} \mathrm{Nb}$. This is because the impact of the boron on fast neutrons above $10 \mathrm{MeV}$ is very small. On the other hand, significant differences are found for the reaction rate of ${ }^{197} \mathrm{Au}(\mathrm{n}, \gamma){ }^{198} \mathrm{Au}$. The reaction rate of ${ }^{197} \mathrm{Au}(\mathrm{n}, \gamma){ }^{198} \mathrm{Au}$ rapidly increases at $0-10$ cm depths in Structure-1 with the depth, and slowly decrease at $10-50 \mathrm{~cm}$ depths. This is because the low energy neutrons rapidly increase at $0-10 \mathrm{~cm}$ depths due to moderation of fast neutrons, and these low energy neutrons are captured by the concrete at $10-50 \mathrm{~cm}$ depths. The reaction rate of ${ }^{197} \mathrm{Au}(\mathrm{n}, \gamma){ }^{198} \mathrm{Au}$ much more rapidly decreases around the boron sheet, since low energy neutrons are effectively captured by the boron sheet.

Figure 8 shows ratios of the reaction rate of the ${ }^{197} \mathrm{Au}(\mathrm{n}, \gamma){ }^{198} \mathrm{Au}$ in the mockups with the boron sheet to that without one. The reaction rate of ${ }^{197} \mathrm{Au}(\mathrm{n}, \gamma){ }^{198} \mathrm{Au}$ at $20 \mathrm{~cm}$ depth in the Sructure- 2 is about $1 / 3$ of that in the Structure-1. The difference between the results in the Sructure- 2 and those in the Sructure- 1 slowly decreases at 25-45 cm depth with the depth. This is due to low energy neutrons moderated in the ordinary concrete. In Sructure-3 and Structure-4, the reaction rate of ${ }^{197} \mathrm{Au}(\mathrm{n}, \gamma){ }^{198} \mathrm{Au}$ decreases in the wider region compared with that in Structure-2. The ratios of the reaction rates of ${ }^{197} \mathrm{Au}(\mathrm{n}, \gamma){ }^{198} \mathrm{Au}$ at 20 and $30 \mathrm{~cm}$ depth in both structures to that in Structure-1 are about $1 / 3$ and 1/4, respectively. The integrated reaction rates of ${ }^{197} \mathrm{Au}(\mathrm{n}, \gamma){ }^{198} \mathrm{Au}$ in the ordinary concrete were estimated by the measured values and their interpolations. They in the ordinary concrete in Structure-2, Stucture-3 and 
Structure- 4 are about $70 \%, 60 \%$ and $60 \%$, respectively, of that in Structure-1. By increasing the number of the boron sheet, the reaction rates of ${ }^{197} \mathrm{Au}(\mathrm{n}, \gamma){ }^{198} \mathrm{Au}$ more decrease, though the construction cost increases. From the experimental study, it is demonstrated that the multi-layered concrete structure with the boron sheet reduces low energy neutrons.

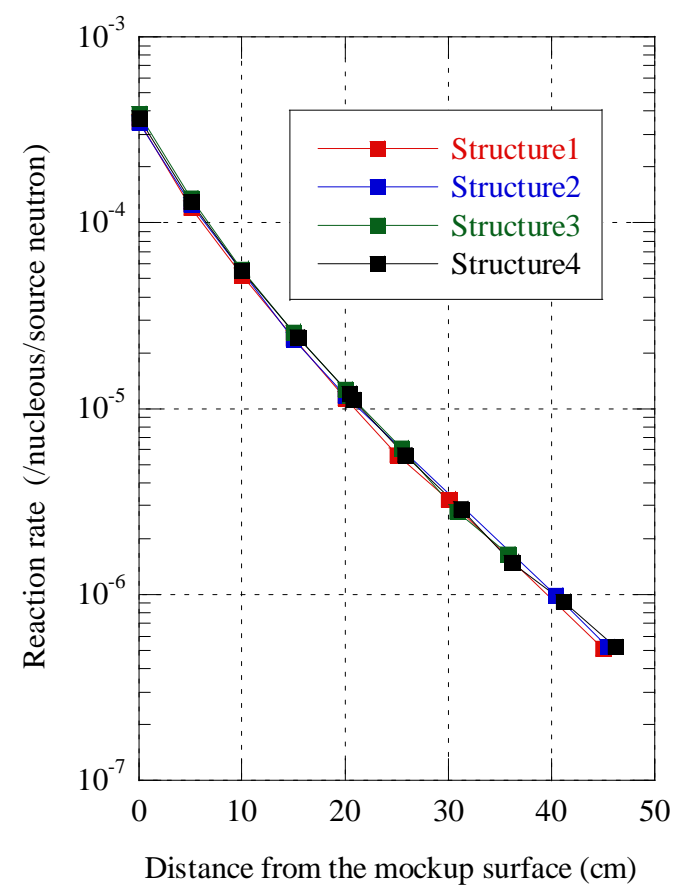

Figure 6. Reaction rate distributions of ${ }^{93} \mathrm{Nb}(\mathrm{n}, 2 \mathrm{n})^{92 \mathrm{~m}} \mathrm{Nb}$ in the multi-layered concrete structure mockups.

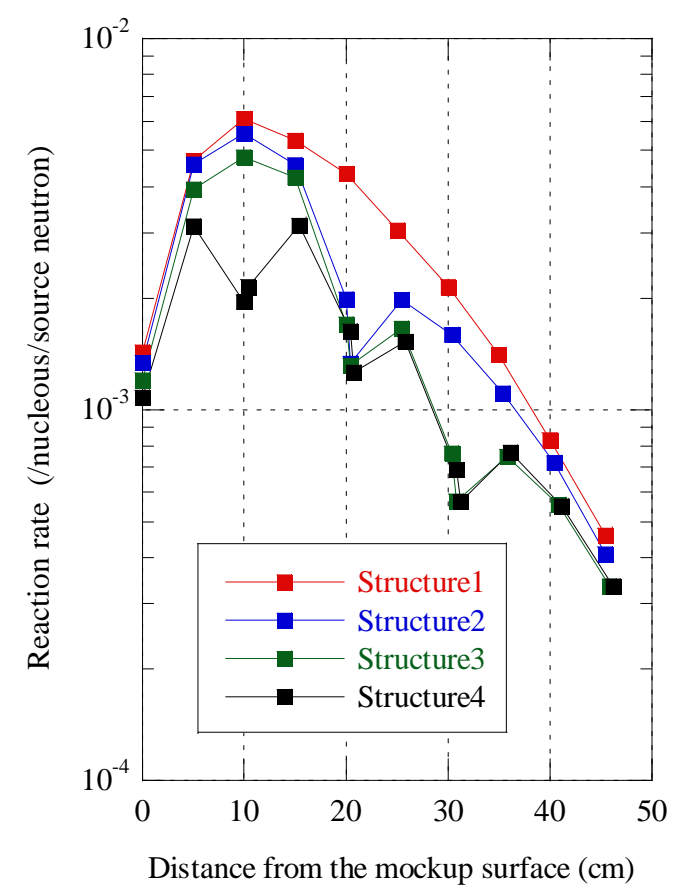

Figure 7. Reaction rate distributions of ${ }^{197} \mathrm{Au}(\mathrm{n}, \gamma){ }^{198}$ in the multi-layered concrete structure mockups.

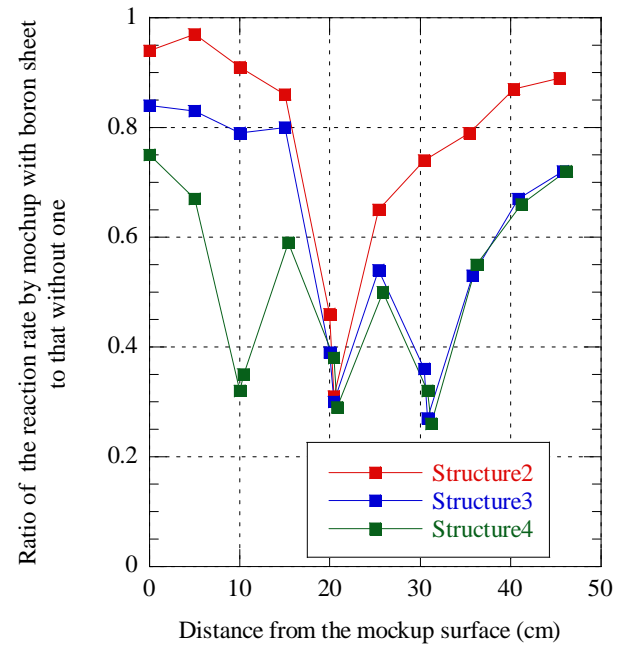

Figure 8. Ratio of the reaction rate of ${ }^{197} \mathrm{Au}(\mathrm{n}, \gamma){ }^{198} \mathrm{Au}$ in the mockups with the boron sheet to that without one.

\section{Conclusion}

We developed a boron sheet, and a new multi-layered concrete structure with it. A DT neutron shielding experiment was conducted by using the multi-layered concrete structure mockups at FNS in JAEA. By inserting the boron sheet, the reaction rates of ${ }^{197} \mathrm{Au}(\mathrm{n}, \gamma){ }^{198} \mathrm{Au}$ at the concrete just behind the boron sheet decreased by factors of about 3 - 4 compared with those in the mockup without the boron sheet. As a result, the integrated values in the ordinary concrete of the reaction rates of ${ }^{197} \mathrm{Au}(\mathrm{n}, \gamma){ }^{198} \mathrm{Au}$ were reduced to $60-$ $70 \%$. It was demonstrated that the multi-layered concrete structure with the boron sheet reduced low energy neutrons, which leaded to less induced activity in concrete walls.

\section{Acknowledgements}

The authors wish to thank Messrs. C. Kutsukake, S. Tanaka, Y. Abe, Y. Oginuma and M. Kawabe for operation of the FNS accelerator.

\section{References}

[1] S. Sato, T. Maegawa, K. Yoshimatsu, K. Sato, A. Nonaka, K. Takakura, K. Ochiai and C. Konno, Development of a low activation concrete shielding wall by multi-layered structure for a fusion reactor, J. Nucl. Mater. 417 (2011), pp. 1131-1134.

[2] X-5 Monte Carlo Team, MCNP - A General Monte Carlo N-Particle Transport Code, Version 5, LA-UR-03-1987, Los Alamos National Laboratory, (2003).

[3] L. Al-dama and A. Trkov, FENDL-2.1, Update of an Evaluated Nuclear Data Library for Fusion Applications, IAEA Report INDC(NDS)-467, International Atomic Energy Agency, (2004). 